\title{
El diseño urbano en frentes fluviales como posibilitador de una nueva "imaginabilidad" urbana: caso ribera central de Rosario (Argentina)
}

\section{Resumen}

El presente artículo indaga sobre la imagen de la transformación de los frentes costeros a través del diseño urbano y el desarrollo de nuevos espacios públicos articuladores entre el tejido y el agua. A partir de los desarrollos realizados por György Kepes y Kevin Lynch, se focaliza especialmente en los conceptos de imaginabilidad y legibilidad. El trabajo se realiza mediante un método cualitativo y la metodología se fundamenta en el enfoque fenomenológico, desarrollando una hermenéutica territorial a través de estudios de casos. Para lo cual, se analizan cuatro transformaciones de frentes costeros relevantes de los últimos 60 años: Baltimore Inner Harbour (EE.UU.), Docklands de Londres (Inglaterra), Ría 2000 de Bilbao (España) y Battery Park, Nueva York (EE.UU.); profundizando posteriormente en el caso de la reconversión ribereña central de Rosario (Argentina). Este caso de estudio es representativo porque el reclamo de cambiar la relación entre la ciudad con su río está presente desde las primeras décadas del siglo XX, solicitando el traslado de las infraestructuras ferro-portuarias (aún activas y de gran relevancia económica) hacia otros sectores, a fin de reconvertir la costa central en nuevos espacios públicos. Sin embargo, es a partir del retorno democrático definitivo en Argentina, a mediados de la década de 1980, que se realizan diversas acciones continuas en el tiempo que permiten invertir la imagen de la ciudad de una urbe que creció de espaldas al río, a dar la cara al Paraná; fortaleciendo así su identidad, estructura y significado. El diseño urbano tiene un rol clave en el cambio de la imaginabilidad urbana. No obstante, a fin de que dichas reconversiones no generen imágenes globales estandarizadas, se requiere la escucha atenta de las demandas de la población, sus valores simbólicos y su patrimonio, dando lugar a las especificidades locales y su identidad particular.

\author{
Cecilia Galimberti \\ Doctora en Arquitectura \\ Investigadora del Centro \\ Universitario Rosario de \\ Investigaciones Urbanas y Regionales \\ (CURDIUR) del Consejo Nacional de \\ Investigaciones Científicas y Técnicas \\ (CONICET). Profesora investigadora \\ de la Universidad Nacional de \\ Rosario (UNR) (Rosario, Argentina) \\ y del Grupo de Investigación \\ ARUCO - Universidad de la Costa \\ (Barranquilla, Colombia). \\ Correo electrónico: \\ cecilia.galimberti@conicet.gov.ar \\ 으이. orcid.org/0000-0001-9030-0143 \\ Google Scholar
}

Recibido: julio 3 de 2019 Aprobado: marzo 26 de 2021

Palabras clave: diseño urbano, espacio público, frente fluvial, imagen, legibilidad. 


\section{Urban Design in river front transformations as an enabler of new urban "imaginability": the case of the central river front of Rosario (Argentina)}

\begin{abstract}
This article inquires into the image of the transformation of river fronts through urban design and the development of new articulating public spaces between the fabric and the water. Based on the developments carried out by György Kepes and Kevin Lynch, the paper focuses especially on the concepts of imaginability and legibility. The work is carried out through a qualitative method and the methodology is based on the phenomenological approach developing a territorial hermeneutic through case studies for which, four relevant waterfronts transformations of the last sixty years are analyzed: Baltimore Inner Harbor (USA); London Docklands (England); Ría 2000 of Bilbao (Spain) and Battery Park, New York (USA), later deepening into the case of the central riverside reconversion of Rosario (Argentina). This case study is representative because the claim to change the relationship between the city and its river has been present since the first decades of the twentieth century, requesting the transfer of rail-port infrastructures (still active and of great economic relevance) to other sectors, in order to restructure the central coast into new public spaces. However, it is from the definitive democratic return in Argentina in the mid-1980s, that various continuous actions have been carried out over time to restructure the image of a metropolis that grew with its back to the river, to become a city facing the Paraná thus strengthening its identity, structure and meaning. Urban design plays a key role in changing urban imaginability. However, in order that these reconversions do not generate standardized global images, it is necessary to listen carefully to the demands of the population, their symbolic values and their heritage, giving place to local specificities and their particular identity.
\end{abstract}

Key words:

image, legibility, public space, urban design, waterfront. 


\section{Introducción}

El diseño urbano se constituye en un campo amplio de intervención a través del cual se viabiliza abordar la complejidad de la ciudad, sus particularidades, diversidad de actores y sus intereses, a fin de comprender sus dinámicas, lógicas y estructura urbana. Se genera así el desarrollo de estrategias que faciliten transformar su morfología a fin de encauzar una mayor calidad espacial y de vida para la población.

En el presente artículo, abordamos el concepto de diseño urbano a partir de los postulados desarrollados en la década de 1950 por György Kepes y Kevin Lynch, posteriormente editados en el libro La imagen de la ciudad, entendiendo el carácter fundacional de sus estudios, dado que en dicho momento histórico se da comienzo a una gran cantidad de investigaciones, abordajes y teorías sobre el diseño urbano. En este sentido, vamos a focalizarnos en el rol del diseño en la transformación de sectores estratégicos urbanos sobre frentes fluviales. Nos referimos a áreas originalmente productivas-portuarias que, luego de quedar obsoletas o en procesos de degradación o abandono, han atravesado procesos de revitalización y regeneración urbana y se convierten en atractoras de diversas actividades y nuevos usos, como, por ejemplo, el turismo.

La regeneración urbana, como explica Peter Roberts (2000), se presenta como el resultado de la interacción entre los factores externos e internos que demandan una respuesta a los desafíos y oportunidades de degradación urbana en un lugar y un arco temporal concreto. Es así que la capacidad del buen diseño urbano y del espacio público resultan clave para favorecer los procesos de regeneración urbana integral (García-Pérez, 2017); especialmente, en la actualidad, se están abordando nuevas miradas en torno a este concepto, dados los intereses y resultados contrastantes en diversos casos de regeneración 
(Castrillo et al., 2014); por lo cual, definiciones más recientes de regeneración se focalizan tanto en las personas como en los lugares (Parkinson, 2014). Asimismo, se genera un cambio en cuanto a la legibilidad en la percepción de sus habitantes, generando, a su vez, nuevas apropiaciones de los espacios públicos junto al agua.

Los procesos de transformación de frentes fluviales comienzan a registrarse a nivel mundial desde la década de 1960 y continuando en la actualidad. La regeneración urbana de frentes fluviales involucra diversos aspectos económicos, sociales, políticos, entre otros, que, a pesar de estructurarse en el desarrollo de nuevos espacios públicos costeros, muchas veces se vinculan con plusvalías urbanas y mercantilización (Navas, 2019); así como disputas antagónicas sobre "lo que es y debe ser la ciudad" que conducen a escenarios de intereses contrastantes (Delgado, 2008), ocasionando muchas veces procesos de gentrificación (Smith, 2006). No obstante, el presente artículo se focaliza en la transformación de la imaginabilidad y la legibilidad de los frentes costeros; por lo cual, se desarrolla el estudio de diversos casos paradigmáticos de reconversión de waterfronts europeos y norteamericanos, para luego profundizar sobre la transformación del frente fluvial central de Rosario en Argentina. Dicho caso es representativo, porque dicha reconversión ocasiona un cambio radical de la imagen urbana de una ciudad que creció de espaldas al río, a convertirse en su principal foco turístico y recreativo.

En este sentido, el presente artículo tiene como objetivo explicar el rol del diseño urbano en la reconversión de espacios para uso público y lograr así una mayor "imaginabilidad"1 urbana (en términos de Kevin Lynch y György Kepes),

\footnotetext{
${ }^{1}$ La imaginabilidad es "esa cualidad de un objeto físico que le da una gran probabilidad de suscitar una imagen vigorosa en cualquier observador de que se trate. Se trata de esa forma, de ese color o de esa distribución que facilita la elaboración de imágenes mentales del medio ambiente que son vívidamente identificadas, poderosamente estructuradas y de suma utilidad. A esto se le podría dar, asimismo, el nombre de legibilidad, o quizás el de visibilidad en un sentido realizado, cuando no sólo es posible ver los objetos, sino que se los presenta aguda e intensamente a los sentidos" (Lynch, 1970, p. 18).
} 
tomando como caso de estudio la ribera central de la ciudad de Rosario en Argentina. En esta ciudad es el reclamo de la población (desde las primeras décadas del siglo $\mathrm{XX}$ ) el motor principal de transformación de su imagen urbana, a través de la revalorización identitaria y patrimonial, con nuevas actividades y usos predominantemente recreativos; estableciendo una nueva imaginabilidad y legibilidad de su frente costero.

\section{Marco conceptual}

El diseño urbano, especialmente desde la segunda posguerra ha tenido un rol central en la planificación y transformación de las ciudades. Especialmente, es importante destacar la refundación de este concepto en la década de 1950, en Estados Unidos, por Kevin Lynch y György Kepes. En un contexto crítico sobre las propuestas del urbanismo ortodoxo, existían diversas miradas que reclamaban un mayor entendimiento de las ciudades frente a los cambios que atravesaban en dicho período. En 1954 la Fundación Rockefeller otorgó la primera beca de financiación en este campo de estudios a Kepes y Lynch (del Centro de Estudios Urbanos del Instituto de Tecnología de Massachusetts -MIT-). Como explica Laurence (2006), el temprano reconocimiento de la importancia de los estudios sobre el diseño urbano por parte de la Fundación Rockefeller ocasionó que estuvieran en la vanguardia de la arquitectura y teoría urbana de posguerra. La primera financiación sobre este tema justamente consistía en un proyecto de investigación básica, formulado por Kepes y Lynch, para estudiar los principios de la percepción humana y el entendimiento del ambiente urbano.

Dicho estudio resulta ser el primero sobre diseño urbano abordado desde la perspectiva del rol de la percepción humana y la legibilidad de las ciudades en torno al hombre y las sociedades. En un ámbito generalizado donde la técnica, la eficiencia económica y el funcionalismo de posguerra eran ampliamente 
dominantes, y a pesar de las críticas posteriores que ha recibido (como ser acusado de un "funcionalismo ingenuo"), dicha investigación fue pionera de numerosos estudios y teorías urbanas posteriores. De manera que, finalmente, terminó transformando el campo general del planeamiento urbano. Gran parte de los desarrollos y resultados obtenidos son publicados en 1960 en el libro La imagen de la ciudad, en el cual solo se indica como autor a Kevin Lynch. No obstante, en el prefacio del libro plantea:

[...] un nombre debería figurar en la portada, junto al mío, si no lo hiciera responsable de las imperfecciones del libro. Ese nombre es György Kepes. El desarrollo detallado y los estudios concretos me corresponden, pero los conceptos subyacentes surgieron a lo largo de coloquios con el profesor Kepes. Me resultaría imposible separar mis propias ideas de las suyas. Para mí, estos años de colaboración con él han sido fructíferos. (Lynch, 1970, p. 7)

En dicho libro se sostiene que "dar forma visual a la ciudad constituye un tipo especial de problema de diseño" y que "sugiere un método por medio del cual se puede empezar a ocuparse de la forma visual en escala urbana, y ofrece algunos principios básicos de diseño urbano" (Lynch, 1970, p. 7); dado que su objetivo consiste en "construir ciudades para el goce de grandes grupos de personas con antecedentes sumamente diversos" (p. 17). Por lo cual, incorpora conceptos clave como: la legibilidad del paisaje urbano, entendida como la facilidad con que pueden reconocerse y organizarse sus partes en una pauta coherente; el rol de la imagen ambiental; y la imaginabilidad entendida analíticamente como identidad, estructura y significado. El análisis realizado por Kepes y Lynch identifica cinco tipos de elementos que se refieren a las formas físicas que constituyen las imágenes de la ciudad: sendas, bordes, barrios, nodos y mojones (Figura 1). 


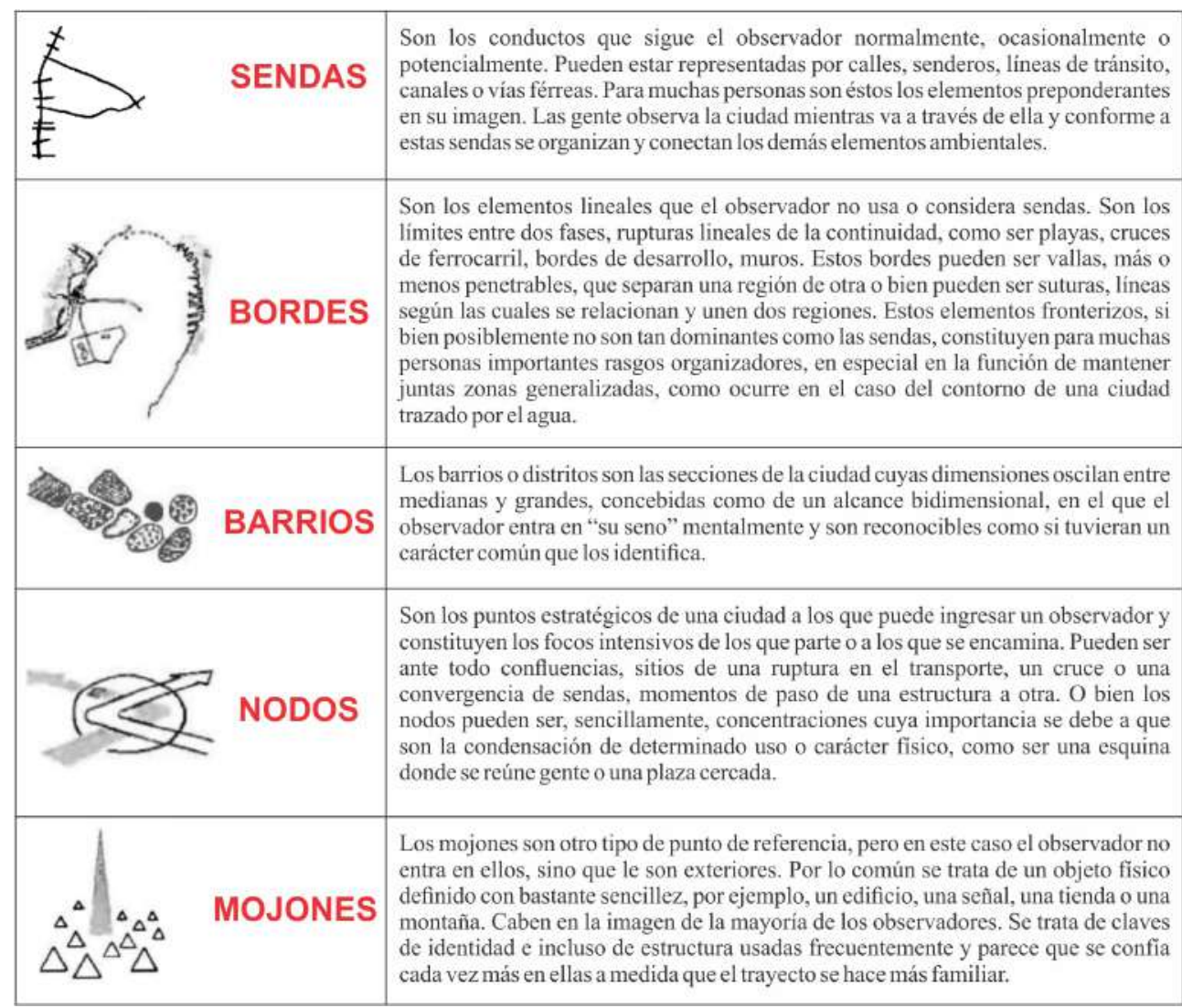

Figura 1. Definiciones de sendas, bordes, barrios, nodos y mojones. Fuente: elaboración propia basada en Lynch (1970).

Esta nueva plataforma de pensamiento sobre el diseño urbano resulta de enorme influencia a diversos autores mundialmente. Distintos teóricos y referentes de diseño urbano, entre 1960 y la actualidad, han profundizado 
y enriquecido este campo de estudios. En 1961, Gordon Cullen en su libro Townscape plantea que el diseño urbano se refiere a la organización adecuada de los elementos visuales. El mismo año, Jane Jacobs publica The Dead and life of Great America Cities, estudio que también llevó a cabo mediante subvención de la Fundación Rockefeller, en el cual fundamentaba cómo las transformaciones que habían registrado las ciudades no correspondían a las reales necesidades de la sociedad, incorporando conceptos relevantes para el diseño de las ciudades que fortalezcan el rol de los ciudadanos, reivindicando la importancia de las calles y el espacio público como espacio de relación.

Asimismo, es de gran relevancia la obra de Colin Rowe, en especial la reconocida Ciudad Collage de 1978 (Rowe y Koetter, 1998), en la cual enfatiza en la diversidad y complejidad de la forma de la ciudad, sosteniendo que es necesario dar lugar a cada fragmento, tanto a la tradición como a la modernidad, a la historia como a la innovación. También es importante mencionar los estudios de Cristopher Alexander, desde la publicación de A Pattern Language: Towns, Buldings, Construction (1977), a Una nueva teoría sobre el diseño urbano (1987), como resultado de los experimentos realizados en 1978 y, más recientemente, los cuatro tomos de The Nature of Order: An Essay on the Art of Building and the Nature of the Universe, en los cuales el hombre, los habitantes locales, sus acciones, eventos, percepciones y pensamientos resultan centrales en el proceso de diseño. Kevin Lynch en 1981, veinte años más tarde de La imagen de la ciudad, publica A Theory of Good City Form, en la cual identifica las condiciones de las buenas formas urbanas, como aquellas que resultan "vital, adecuada al lugar, igualitaria, accesible y susceptible de control local" (Monclús, 2016, p. 44).

Los avances en las últimas décadas han decantado en nuevas concepciones más abiertas del diseño urbano, más centradas en los procesos de reconfiguración del espacio. Es decir, una preocupación tanto "en el diseño de los 'procesos' 
que generan la forma urbana como en el diseño de los 'productos' construidos que dan forma a la ciudad" (Munizaga, 2014, p. 32). Estos enfoques han llevado a estrategias de integración de la acción humana, concentrándose en la articulación de problemas y construyendo simultáneamente nuevos espacios de diálogo e interconexión entre los actores y disciplinas vinculadas a la configuración del medio construido (Munizaga, 2014).

Es así que el diseño urbano se basa intrínsecamente en las necesidades y valores de la sociedad, cuyo deber es responder a la multiplicidad de prácticas, pensamientos y percepciones de los distintos habitantes, siendo inclusivo y facilitando el encuentro y las diversas apropiaciones de los actores que forman parte de la ciudad. En este sentido, el rol de la imagen urbana es clave; siguiendo a Francesc Muñoz, "hoy día, parece evidente que la imagen se ha convertido en una condición necesaria del proceso mismo de la transformación urbana, hasta tal punto que se puede considerar como el primer elemento necesario para producir ciudad" (2008, p. 57).

\section{Materiales y métodos}

El trabajo se realiza a partir de un método cualitativo y la metodología se fundamenta en el enfoque fenomenológico, desarrollando una hermenéutica territorial a través de estudios de casos. Como explica Sautu (2005, pp. 42-43), el estudio de caso se caracteriza por tres rasgos: 1) Es particularístico, dado que está focalizado sobre una situación, programa, fenómeno en particular, aun cuando en su elección se reconozca que es un caso entre otros con los que comparte ciertos rasgos; 2) Tiene un alto contenido descriptivo que permite mostrar sus complejidades, mostrando la influencia del tiempo y las secuencias en que los hechos vinculados al caso tienen lugar; $y, 3$ ) Tiene la cualidad heurística que permite abordar explicaciones en términos de cómo suceden los hechos y por qué (Galimberti, 2014). A fin de abordar dicha complejidad 
se utilizan diversas estrategias para producir esta evidencia empírica, como el análisis de documentos, entrevistas y la observación directa del investigador.

Se parte del análisis previo de cuatro estudios de casos que resultan referentes sobre el diseño urbano en espacios fluviales: Baltimore Inner Harbour (Baltimore, Estados Unidos), Docklands (Londres, Inglaterra), Ría de Bilbao (España) y Battery Park (Nueva York, Estados Unidos); en los que se han abordado el análisis de diversas fuentes secundarias y recorridos exploratorios del territorio en cada uno de ellos. El análisis previo de estos casos nos da indicios sobre los componentes y tópicos recurrentes y particulares del diseño urbano aplicado en cada uno, que establece un corpus analítico para indagar al caso de estudio argentino abordado en profundidad. Se aborda, entonces, el cambio de imaginabilidad de la ribera de Rosario, que pasa de identificar un "divorcio entre la ciudad y su río" (Della Paolera et al., 1935, p. 12) a principios del siglo XX, a una nueva transformación de su costa central, entre la década de 1980 y la actualidad, desarrollando una nueva imagen urbana. Para su estudio se han utilizado diversos materiales, como: planes urbanos, cartografías, publicaciones periódicas (diarios y revistas), planos y folleterías turísticas; se efectuaron entrevistas a pobladores y visitantes de Rosario y se realizó la observación directa a través de recorridos exploratorios del territorio.

\section{Análisis de cuatro casos referentes norteamericanos y europeos del diseño urbano de waterfronts}

\section{Baltimore (Estados Unidos): Baltimore Inner Harbour}

La reconversión del frente fluvial del río Patapsco, iniciada en la década de 1960, resulta la primer gran transformación de sectores centrales portuariosproductivos en un nuevo programa de usos mixtos. El objetivo central consiste en transformar a Baltimore en una ciudad atractiva como parque 
regional turístico-recreativo. Se encarga el Plan de la reconversión a la firma de planeamiento Wallace, McHarg, Roberts \& Todd (WMRT). Es importante destacar que uno de los responsables del proyecto es lan McHarg, quien (al igual que Kepes, Lynch, Jacobs y Alexander) había sido beneficiado por una subvención de la Fundación Rockefeller para generar nuevas bases sobre la renovación urbana.

Es así que la firma WMRT diseña un espacio público ribereño continuo, logrando un nuevo paseo urbano sobre el río, generando nuevos caminos, parques y muelles de acceso público. Diferentes atractivos y programas de actividades se incluyen en el diseño del nuevo Inner Harbour. Durante la década de 1970, se construyen: el Centro de Ciencias de Maryland, el World Trade Center, el Music Pavilion, el Acuario de Baltimore y el Pabellón de Mamíferos Marinos. A su vez, se gestionan nuevos recorridos recreativos en barcos, submarinos, visitas portuarias y navegaciones a la bahía Cheasapeake.

Las ferias y los festivales atraen la atención al nuevo frente costero. Estos se posicionan como la estrategia publicitaria principal para la atracción de turistas al nuevo Baltimore. Como explica David Harvey (2008), la Feria de Baltimore se convierte en un núcleo de atracción de multitudes que acuden a la zona céntrica de la ciudad. Esta transformación de frente fluvial se convierte, para algunos, en clave de éxito incuestionable. La ciudad en 20 años pasa de presentar problemáticas de deterioro, abandono y conflictos económicosproductivos, a ser uno de los focos turísticos principales de la región con 7.500.000 turistas anuales. Sin embargo, para otros, la transformación de Baltimore representa la Disneysificación de un centro urbano. Es decir, la ciudad se transforma en una mera escenografía sobre la cual realizar espectáculos con el objetivo primario de atraer el turismo a fin de obtener réditos económicos. Se sucede así una "comercialización institucionalizada de un espectáculo más o menos permanente" (Harvey, 2008, p. 111); dado que 
existen factores que no son integrados al resto del programa; por ejemplo: los conflictos sociales, la revalorización de la identidad local, la arquitectura de las nuevas infraestructuras, entre otros temas (Galimberti, 2015) (Figura 2).

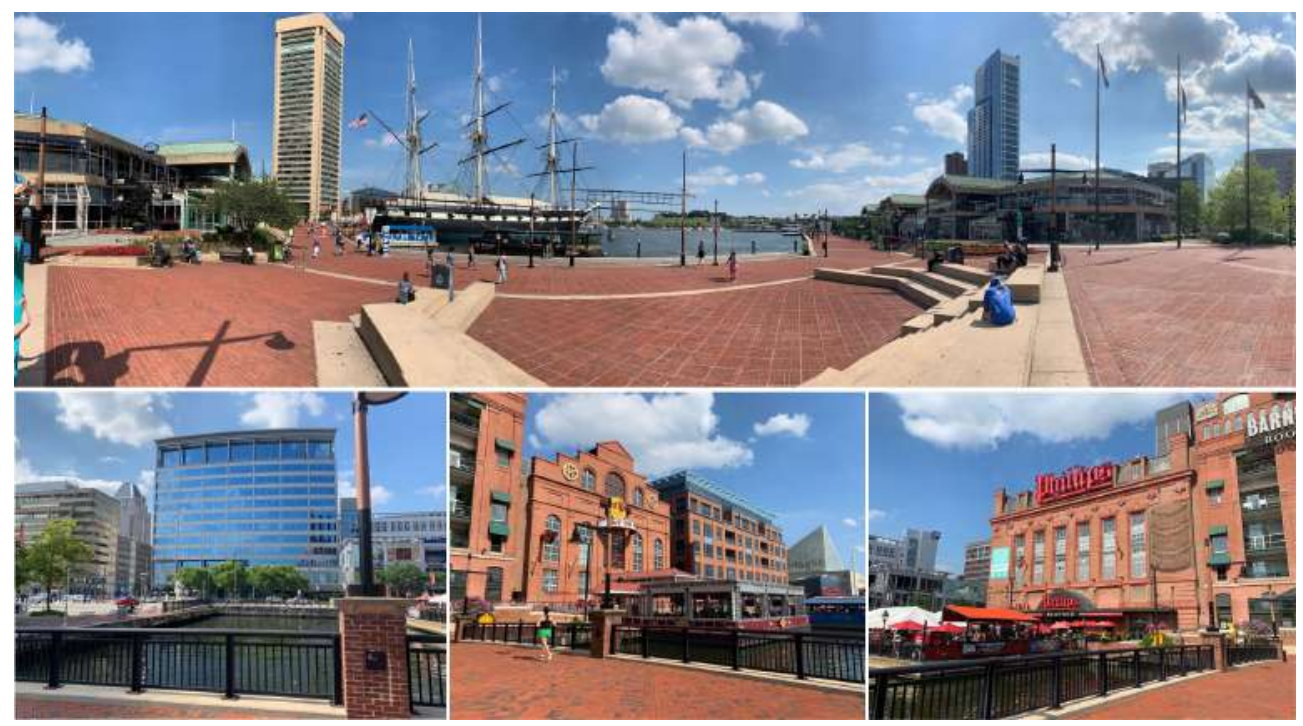

Figura 2. Baltimore Inner Harbour (Baltimore, Estados Unidos). Fuente: fotografías de la autora.

\section{Londres (Inglaterra): Docklands}

La reconversión de áreas portuarias e industriales del río Támesis, ubicadas en un lugar estratégico de Londres, ha conducido a uno de los desarrollos de waterfronts más paradigmáticos a nivel global. Este sector portuario, a fines de 1970 se encontraba obsoleto y degradado. En 1980 el Gobierno local encargado del Planeamiento y Usos del suelo de Londres crea el consorcio 
"London Docklands Development Corporation", caracterizado por una fuerte presencia de la inversión privada. El objetivo central consistía en refuncionalizar los edificios existentes y los sectores urbanos aledaños, atrayendo nuevos componentes comerciales y administrativos, como también desarrollando equipamientos y complejos residenciales para que la gente viva y trabaje en el mismo sector (Figura 3).

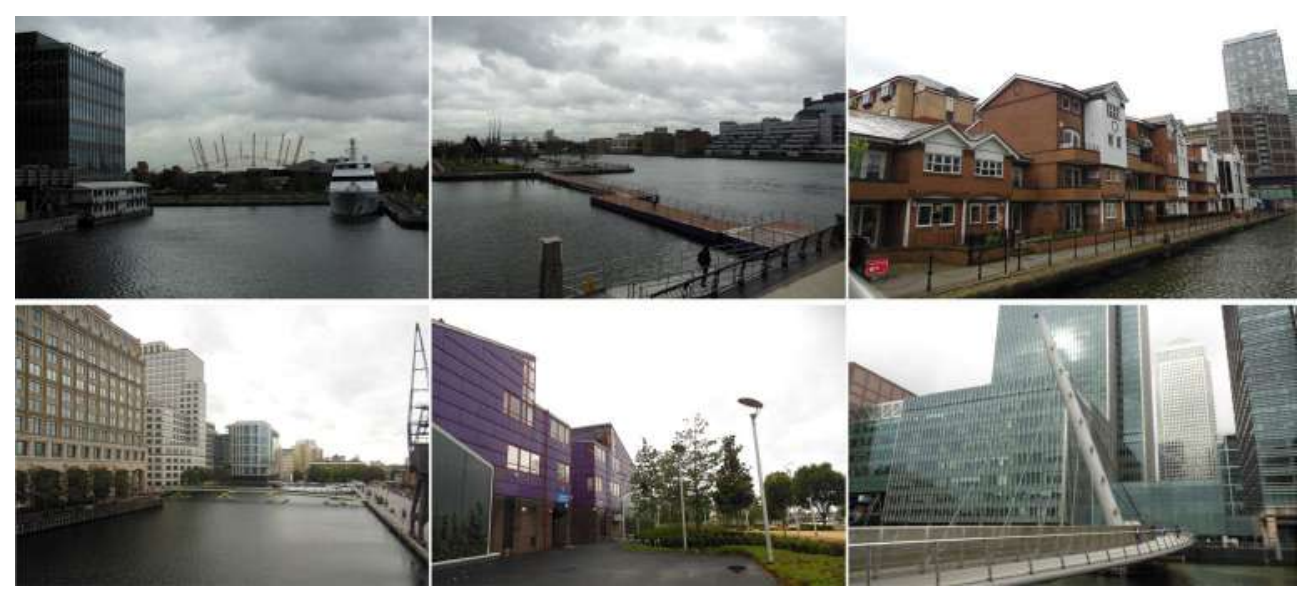

Figura 3. Docklands (Londres, Inglaterra). Fuente: fotografías de la autora.

Si bien se plantea la revalorización de galpones, muelles y complejos de viviendas originales de trabajadores portuarios, esta acción queda en un segundo plano frente al enorme incremento de la superficie edificada que se incorpora, junto a un gran desarrollo de nuevas torres y arquitecturas de autor que generan la atracción de capitales internacionales y grupos de alto poder adquisitivo que ocasiona una nueva morfología (muy alejada de la caracterización original). Esto conduce a que se produzcan numerosos 
procesos de gentrificación, obligando a los habitantes locales a desplazarse a otros sectores.

Este proyecto nos hace reflexionar sobre el rol del diseño urbano y sobre los intereses que responden sus lineamientos. Dado que, si bien este gran proyecto logra reposicionar el área dentro de la ciudad, generando nuevas e importantes centralidades $^{2}$ junto al desarrollo de diversos parques y recorridos junto al río, también acarrea diversos procesos de desigualdad para los pobladores originales del área que son desplazados por otros actores atraídos por las nuevas cualidades de Canary Wharf.

\section{Bilbao (España): el Guggenheim junto a la ría}

Bilbao se encuentra sobre la ría del Nervión, en el País Vasco. Su sector central, denominado Abandoibarra, resulta un histórico enclave productivo-portuario de 35 hectáreas de extensión. Especialmente, se destacan los astilleros de Euskalduna, el puerto comercial y una gran playa ferroviaria de Renfe. Sin embargo, entre las décadas de 1970 y 1980, las instalaciones portuarias se trasladan hacia la desembocadura del río al mar, se reubican las infraestructuras ferroviarias y los astilleros cierran. Bilbao atraviesa un contexto de profunda crisis, pérdida de empleos y deterioro de sus áreas centrales urbanas.

A través de un plan integral de transformación para diferentes sectores urbanos, en 1989 se presenta el Plan General de Ordenación Urbana de Bilbao (cuya gestión se encarga a la Asociación Bilbao Ría-2000). Se define un cambio de usos de suelo, promoviendo una nueva centralidad a través de un programa mixto de dotación de nuevas áreas residenciales, de negocios, administrativos y culturales, junto a la dotación de equipamientos y espacios públicos junto a la ría. Pero, es recién en 1999 que se aprueba el Plan Especial de Reforma Interior 
de Abandoibarra. Sin embargo, en 1993 ya había iniciado la construcción del Museo Guggenheim, equipamiento que ocasionará un cambio trascendental para la localidad (inaugurado en 1997). Como explica Rodríguez (2002), se produce un "efecto Guggenheim", dado que este influye en gran medida sobre el mercado inmobiliario, con un aumento notable de la valorización del suelo (ocasionando cuantiosas plusvalías), acompañada de una fuerte campaña de marketing urbano que plantea a la ciudad como un escenario de proyectos de reconocidos arquitectos internacionales (como Gehry, Pelli, Foster, Calatrava, entre otros).

El museo proyectado por Frank Gehry ocasiona un impacto mundial, de manera que resulta un disparador indiscutido para reposicionar a Bilbao, de un enclave productivo deteriorado y obsoleto en crisis, a un foco turístico internacional. La transformación urbana de Abandoibarra suscita tanto críticas como alabanzas. Por un lado, Bilbao que se encontraba "de espaldas a la ría" ${ }^{\prime \prime}$ se convierte en un nuevo paseo continuo junto al agua, articulando los diversos sectores de la ciudad y generando conexiones con distintos usos y actividades. A su vez, se logra revitalizar tanto a la ciudad como también lograr su reactivación económica a partir de su diseño urbano. No obstante, también genera críticas vinculadas al rol del capital, al fuerte incremento del valor del suelo (generando el desplazamiento de habitantes locales) y, sobre la fuerte operación de marketing en torno al Guggenheim, tiene como principal objetivo cambiar la imaginabilidad de "los otros" (referido al ámbito internacional) más que a la de los propios habitantes (Figura 4). 


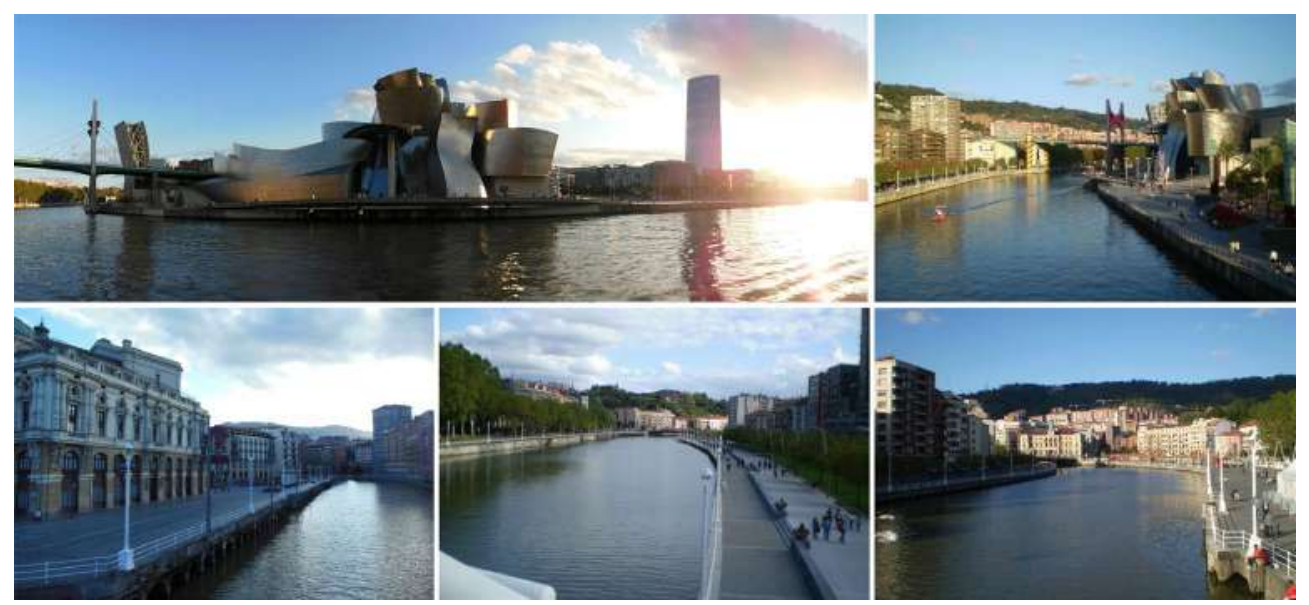

Figura 4. Ría de Bilbao (País Vasco, España). Fuente: fotografías de la autora.

\section{Nueva York (Estados Unidos): Battery Park}

El sector de Battery Park, localizado en la cosa sur de Manhattan (Nueva York), presenta diversas transformaciones y vicisitudes a lo largo del tiempo. En 1968 se realiza un primer máster plan para este sector, de una mirada más cercana al urbanismo moderno, el cual es criticado y finalmente desestimado. Principalmente, esta área se transforma y se amplía, en torno al terreno ganado al río por parte de los escombros generados de las excavaciones realizadas para la construcción de las torres del World Trade Center, siendo completado en 1976. Un nuevo máster plan se realiza en 1979, el cual recibe opiniones contrapuestas, dado que, por un lado, configura la renovación de 37 hectáreas estratégicamente ubicadas para usos mixtos, junto a la dotación de nuevos equipamientos y actividades; pero, por otro, es considerado un "ghetto para ricos", tendiendo a generar una mayor estratificación social y 
careciendo de suficientes espacios verdes y conexiones con el resto de la ciudad (Breen y Rigby, 1994).

A poco tiempo de su desarrollo, en la década de 1990, sus espacios públicos presentaban gran deterioro y estado de abandono. Por ello, se comienza un proyecto de renovación integral del parque, a través de la construcción de un paseo junto al agua y la reconstrucción del dique. Sin embargo, el World Trade Center, a comienzos del siglo XXI, ocasiona que vuelva a cambiar la historia de este sector. Luego del atentado a la Torres Gemelas, el 11 de septiembre de 2001, esta área fue el emplazamiento elegido para efectuar tareas de emergencia, logística de rescate y evacuación. A su vez, todo el sector bajo de Manhattan cambia, especialmente el área de Battery Park se transforma a partir de dicha tragedia.

Posteriormente al ataque, se generan nuevas sendas de paseo junto al río Hudson, una nueva área forestada paisajística (inaugurada en 2005), un jardín comunitario y la incorporación de nuevos equipamientos, árboles y áreas verdes. Luego de eventos meteorológicos (como el Huracán Sandy en 2012), se producen pérdidas materiales que son nuevamente subsanadas. En este sentido, este parque se constituye en un sector resiliente, pero cargado de identidad, incorporando monumentos y recordatorios de los sucesos de la historia de Nueva York. Cotidianamente es visitado, tanto por neoyorquinos como por miles de turistas que visitan cotidianamente la ciudad (Figura 5). 

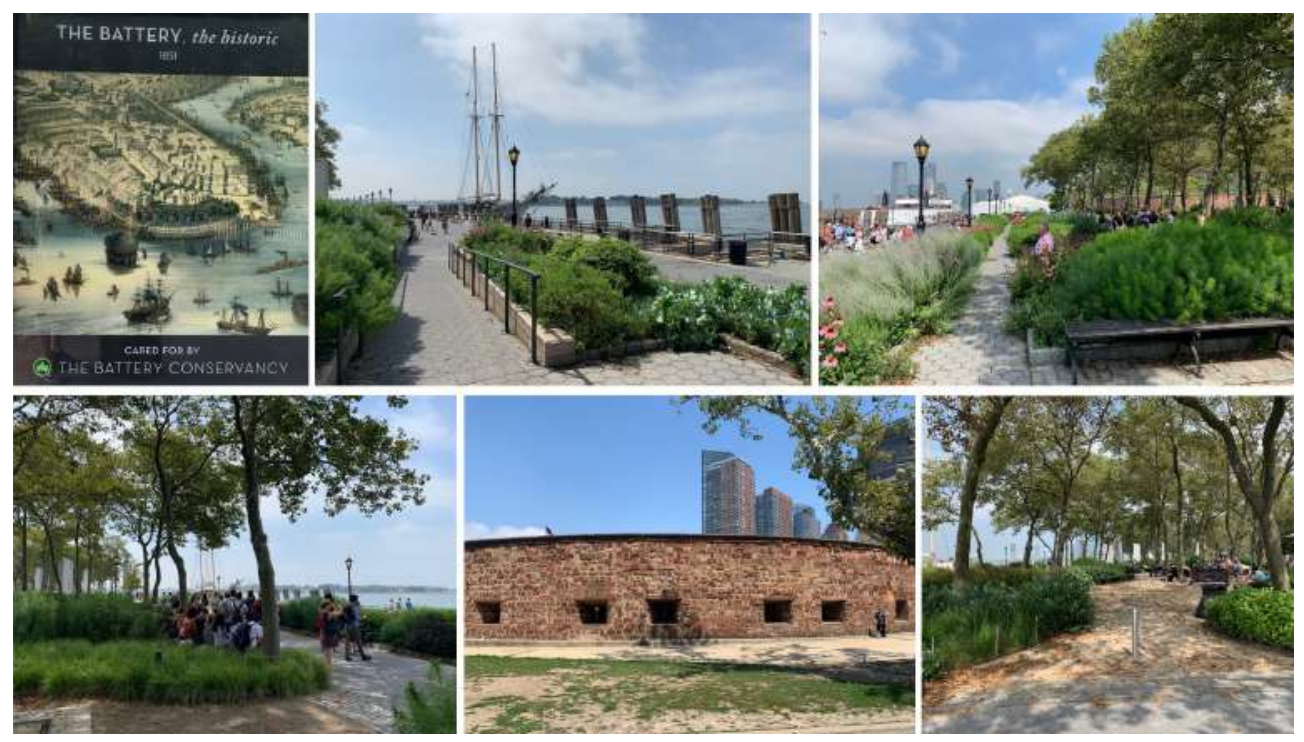

Figura 5. Battery Park (Nueva York, Estados Unidos). Fuente: fotografías de la autora.

Análisis de la transformación de la ribera central de la ciudad de Rosario, Argentina

La ciudad de Rosario se localiza en la ribera occidental del río Paraná. Esta urbe surge y se desarrolla, a mediados del siglo XIX, en torno al fuerte desarrollo de las actividades portuarias y ferroviarias. En la costa central de la ciudad se incrementan aceleradamente estos imponentes establecimientos productivos y, simultáneamente, van creciendo rápidamente las áreas residenciales debido a una gran cantidad de inmigrantes. 
Por lo cual, si bien Rosario debe su crecimiento a las actividades ferro-portuarias, siendo símbolo de su identidad más profunda, desde las primeras décadas del siglo XX surge un malestar en torno a dichos componentes ubicados en el corazón de la ciudad. Esto se debe, principalmente, a los problemas de higiene que ocasionaban estos usos; así como las infranqueables rejas y paredones que separaban la costa con el resto de la ciudad. El imaginario colectivo comienza así a plantear que la ciudad creció y se desarrolla de espaldas al río, debido a la condición de barrera que resultan dichas infraestructuras. La imagen del borde impenetrable de la costa central también se refleja desde dicha época por sus visitantes. Por ejemplo, en diciembre de 1933, Federico García Lorca visita la ciudad de Rosario y al Ilegar a la ribera y ver a lo lejos la magnitud del Paraná, pregunta: " «¿Tenéis un río?». De inmediato, viendo la verja: «¿Por qué lo habéis encerrado?»" (La Capital, 2013). Por esto, desde el primer Plan Regulador de la ciudad (iniciado a fines de la década de 1920 y presentado en 1935):

[...] la ciudad ha quedado encerrada [...] por la presencia de esta verdadera muralla que, en la región costanera, ha desvinculado totalmente a la ciudad de su grandioso río. Por tal causa, la población de Rosario ignora la presencia del majestuoso Paraná que corre a pocos metros de sus barrios más viejos y activos. (Della Paolera et al., 1935, p. 12)

Sumado al reclamo por la escasez de espacios verdes, se propone desde dicho plan la liberación de la costa central de usos productivos, solicitando su traslado hacia el norte y el sur de la ciudad, a fin de reconvertir la ribera con nuevos parques y actividades recreativas-deportivas. Sin embargo, a diferencia de los casos anteriores, Argentina (como gran parte de los países de América Latina) presenta una gran inestabilidad política durante el siglo XX, dado que registra diversos golpes de Estado que interrumpen gobiernos democráticos con dictaduras militares, que, sumados a crisis económicas, imposibilitan la continuidad de las obras para la transformación anhelada (realizándose algunas intervenciones puntuales, como la creación del Parque Nacional a la Bandera y el Parque Urquiza en antiguos predios ferro-portuarios). 
No obstante, la imagen de una sociedad alejada de su río es persistente en el transcurrir de las décadas siguientes. La prensa periódica incorpora frecuentemente en sus páginas dicho imaginario; por ejemplo, en 1954 indica: "Rosario fue desgarrado de su gran río Paraná [...] El puerto [...] levantó un cerco infranqueable entre población y río. Y la ciudad quedó amputada de su Paraná" (La Capital, 1954), reclamando a su vez que "Hora es que se piense en su recuperación [...] Urge, pues, pensar en la reincorporación del Paraná a su urbe [...] Lo exige el nuevo cuadro de demandas, no solamente materiales sino también espirituales, de nuestra población" (La Capital, 1954).

Es a partir del retorno democrático definitivo en Argentina, en 1983, que se inicia la anhelada reconversión del frente fluvial desde diversas acciones continuas en el tiempo. El proyecto que marca el inicio de esta gran reconversión es el Parque España, encargado al estudio catalán MBM (Martorell-BohigasMackay). El rol del espacio público, la revalorización de los componentes históricos identitarios de la ciudad, la articulación del río con diversas sendas perpendiculares a él y la generación de un paseo, senda continua, paralelo al mismo, constituyen las claves de su diseño urbano. Justamente con la inauguración del Complejo Centro Cultural Parque España en 1992 se refuerza el cambio de imagen de la ribera iniciada en la década anterior, de manera que se lo considera "un verdadero balcón al río recuperado para todos los rosarinos a través de la recuperación de un espacio urbano hasta hoy virtualmente desaprovechado" (La Capital, 1992).

En los años siguientes se elaboran diversos planes y propuestas para poder continuar la transformación total de la ribera. Es importante destacar que, en la década de 1990, ya se habían inaugurado o se encontraban en estado de transformación avanzada muchos de los casos abordados en el apartado anterior, siendo referentes internacionales sobre nuevo diseño urbano de waterfronts. A su vez, también están consolidados internacionalmente los postulados que 
plantean el rol de la ciudadanía, sus prácticas, percepciones y actividades como componentes clave en el proceso de diseño urbano. (Figura 6).

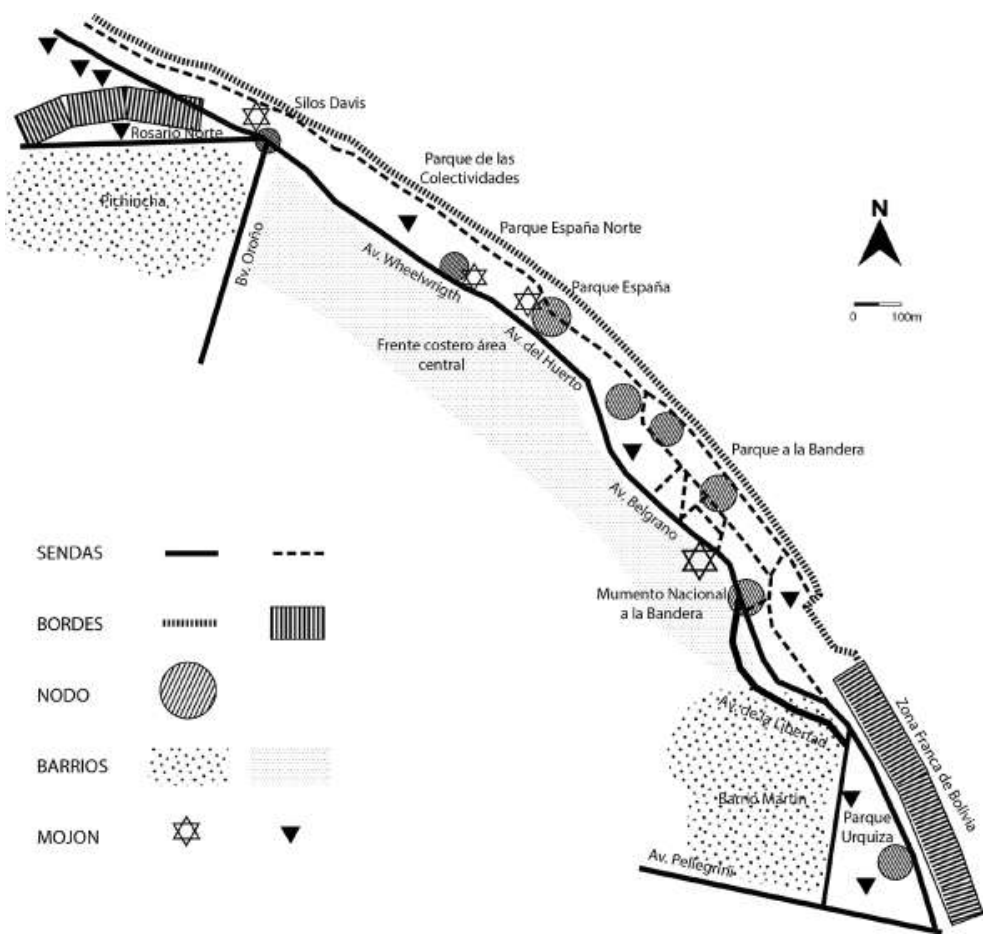

Figura 6. Nueva imagen urbana del frente costero del Área Central de Rosario. Fuente: elaboración propia.

Se continúa así la transformación de toda la costa de usos originalmente productivos-portuarios en una nueva sucesión de espacios públicos. A su vez, el rol de la identidad y revalorización de los componentes de la historia de la localidad también resulta pieza central en el proceso de diseño, de 
manera que se seleccionan diversas construcciones y elementos del puerto y el sistema ferroviario a fin de reconvertirlos para nuevas actividades, mayormente culturales y recreativas, para toda la sociedad. Se generan nuevas sendas, nodos y mojones; transformando la condición negativa del borde fluvial (de la condición de límite, de algo que separa), a una nueva condición positiva, abordando el borde como aquel espacio de interfase que conecta el tejido urbano con el río. (Figura 7).

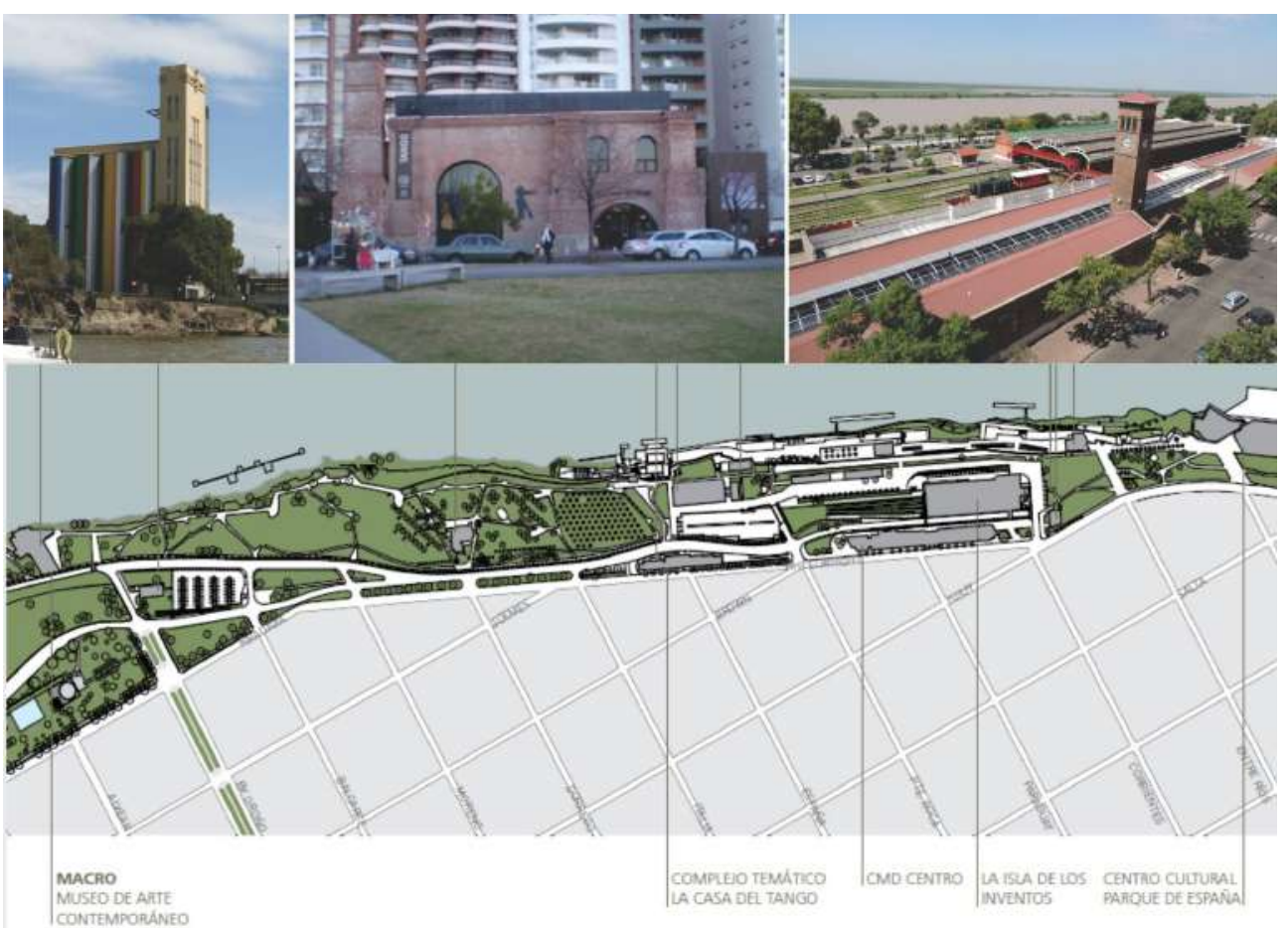

Figura 7. Transformación de la costa central: sector Parque de las colectividades y Parque España Norte. Fuente: Municipalidad de Rosario (2011) y fotografías de la autora. 
Entre las intervenciones realizadas, que responden a un plan integral (Plan Maestro de la Costa), se destacan: A) la creación de una nueva senda, denominada Pasaje Juramento, que conecta la plaza principal, 25 de Mayo, con el Monumento a la Bandera, inaugurado en 1999. B) La refuncionalización de los antiguos galpones portuarios de almacenaje de granos y productos; se inicia con su restauración para albergar el Centro de Expresiones Contemporáneas (CEC), un espacio de actividades culturales y artísticas principalmente dedicado a los jóvenes, localizado junto al Parque España e inaugurado en 1995, continuado con la creación en el galpón lindero del Centro de la Juventud y, en los últimos años, se constituye la reconversión del resto de estas infraestructuras para diversos usos culturales. C) La transformación de los silos Davis en el actual Museo de Arte Contemporáneo de Rosario (MACRO) en 2004. D) La reconversión del Complejo de la exEstación Rosario-Central, la cual es preservada pero readaptada para nuevas funciones administrativas (en ella se aloja el Centro Municipal de Distrito Centro) y un espacio lúdicorecreativo para los niños denominado "Isla de los Inventos"; asimismo, las instalaciones correspondientes a los tanques de agua ferroviarios se refuncionalizan en el Centro Cultural Casa del Tango. E) Las estaciones ferroviarias: "Oeste Santafesino" en el actual parque Urquiza y "Rosario Norte" en el sector conocido como Puerto Norte, a fin de albergar nuevos usos culturales, administrativos y educativos. (Figura 8). 


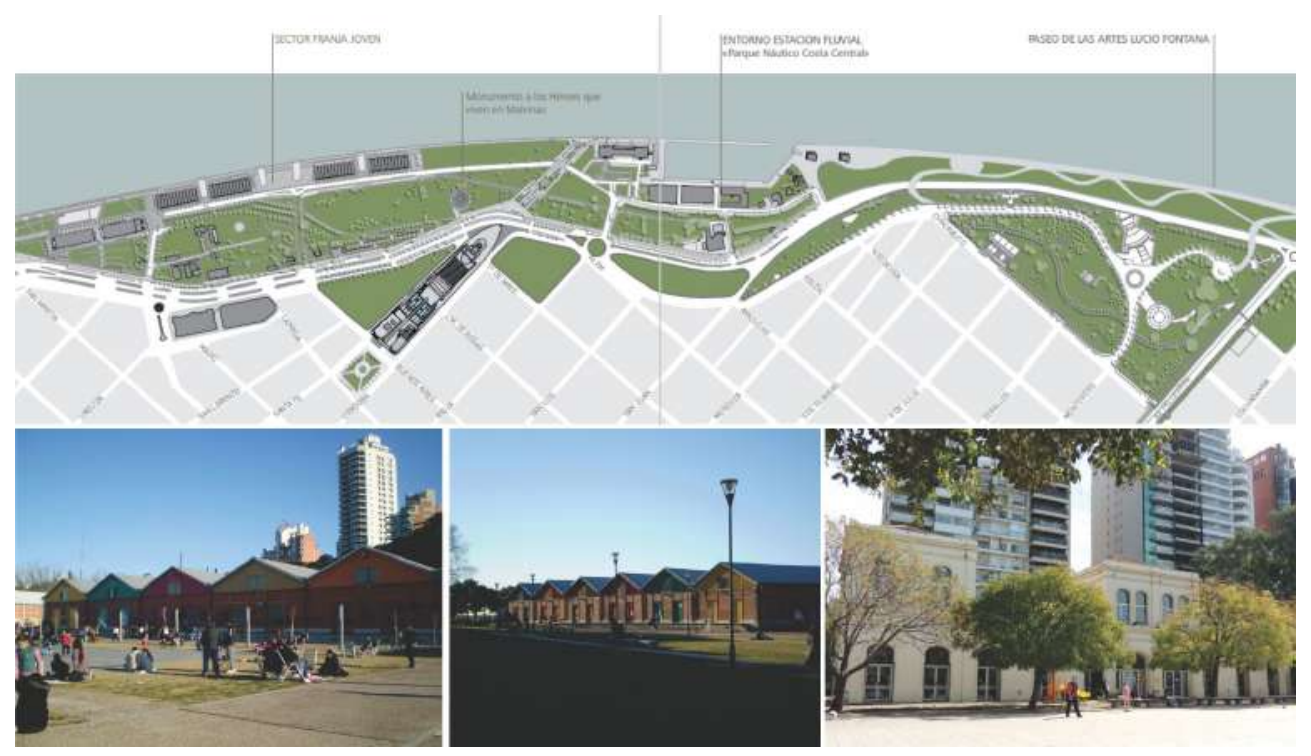

Figura 8. Transformación de la costa central: sector Parque Nacional a la Bandera. Fuente: Municipalidad de Rosario (2011) y fotografías de la autora.

Por otra parte, es importante destacar la apertura de nuevas sendas (mayormente peatonales, pero también vehiculares) para asegurar la continuidad de los recorridos como el acceso a este espacio desde los diferentes barrios de la ciudad. También, se procede a la forestación y dotación de equipamientos, bancos, juegos para niños, componentes para realizar ejercicios físicos, luminarias, entre otros. Es así que la población desde las primeras reconversiones ribereñas asiste cotidianamente a su ribera, cambiando totalmente su imaginabilidad, dado que se convierte el borde costero, concebido como barrera o límite, en un borde articulado entre los diversos barrios con la incorporación de sendas, nodos y mojones que actúan conjuntamente definiendo una nueva imagen ambiental. Entrevistas realizadas a diferentes habitantes de Rosario (de origen 
y residentes recientes) coinciden mayormente, al consultarles sobre el sector más representativo de la ciudad y al que eligen mayormente para sus prácticas recreativas y de ocio, en la ribera central de la ciudad (junto a su Monumento Nacional a la Bandera) (Figura 9).
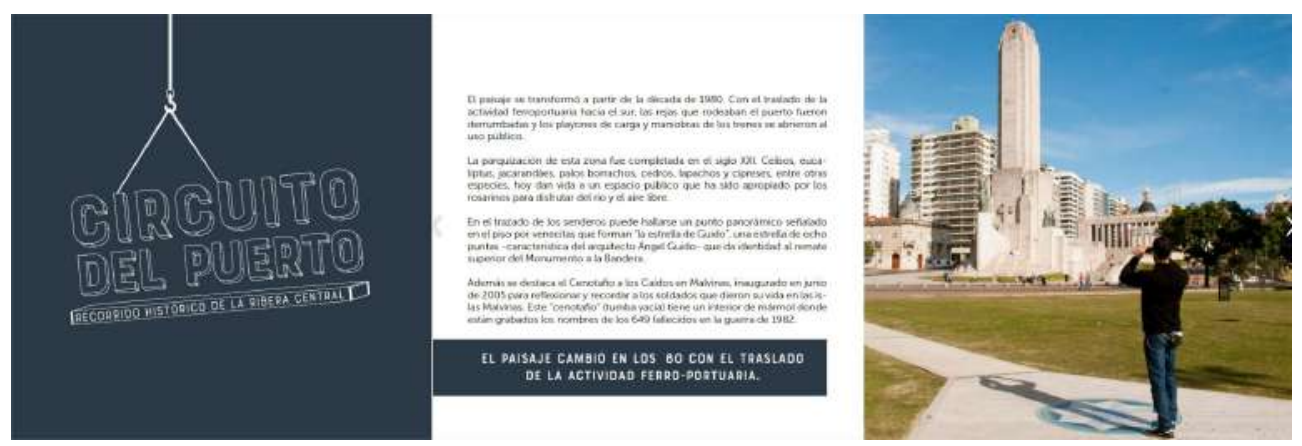

Figura 9. Fragmento del folleto turístico correspondiente al "Circuito del puerto. Recorrido histórico de la ribera central". Fuente: Ente Turístico Rosario (ETUR).

Por otra parte, es relevante destacar que históricamente Rosario nunca se percibió a sí misma como turística; es más, se separaba de dicha condición. Sin embargo, la transformación de su frente costero también resultó atractiva para muchos visitantes. De este modo, las políticas turísticas, especialmente desde los primeros años del siglo XXI junto a la concreción de las obras ya mencionadas, tienen como foco principal a la costa del Paraná. Esto se refleja en las cartografías turísticas, que prácticamente solo representan la ribera, en la folletería y los recorridos sugeridos para los visitantes, como también en la prensa nacional. Por ejemplo, el diario Clarín de Buenos Aires en su sección viajes en 2015 propone como destino: "Rosario, de cara al río Paraná" con su "renovada costanera invita a pasear entre parques y atractivos culturales", manifestando, además, que posee "la costanera más larga del país" (Clarín, 2015). 
A pesar de la nueva imagen urbana de la costa central ocasionada por las transformaciones realizadas principalmente entre 1985-2005, posteriormente, en sectores costeros aledaños, como el área denominada Puerto Norte, entre 2005-2020 se producen nuevas intervenciones que incluyen privatizaciones de espacios ribereños destinadas a áreas ejecutivas-habitacionales de alto poder adquisitivo. De manera que, como se ha verificado en otros ejemplos mencionados (como Docklands, en Londres), se tiende a una gentrificación de los habitantes originales de esos barrios rosarinos (en especial, barrios Refinería y Talleres).

En este sentido, el diseño urbano en la actualidad presenta grandes desafíos, a fin de poder dar lugar a los reclamos y necesidades de los distintos actores presentes en las ciudades y el territorio, revitalizando y regenerando sectores degradados, pero desde la mirada atenta de la identidad local, a fin de evitar resultados genéricos y globales, lejanos al propio lugar. Asimismo, debe dar lugar a la diversidad de actividades de la población, evitando que los habitantes locales sean desplazados por otros liderados por las dinámicas del mercado y el capital.

\section{Discusión}

Los frentes fluviales constituyen espacios de controversia y debate, registrando dinámicas e intereses contrastantes. Siguiendo a Desfor et al. (2011), las ambigüedades y complejidades que caracterizan los procesos de cambio de los frentes costeros pueden sintetizarse bajos los conceptos de "permanencias y flujos". Este par dialéctico (opuestos, pero estrechamente vinculados entre sí) es representativo desde los orígenes portuarios (elementos y componentes construidos y morfológicos que permanecen en el tiempo, así como los flujos de mercancías, de intercambio entre diversas regiones del mundo). Pero también están presentes en la contemporaneidad, a través de las persistencias de ese pasado (materiales e inmateriales) junto a las 
demandas globales, el mercado y las tendencias económicas (dinámicas) que tienden a borrar las identidades locales. Ante este contexto, Francesc Muñoz (2008) plantea que ciudades muy diferentes (por ejemplo, en localización, extensión, cultura y sociedad) atraviesan transformaciones similares que acaban produciendo un paisaje estandarizado y común.

Justamente los primeros casos de reconversión de waterfronts paradigmáticos a escala mundial, como son los ejemplos presentados de Baltimore y Londres (Docklands), registran una pérdida de la individualidad del lugar, a través del desarrollo de prácticas público-privadas que incorporan ferias, festivales, acuarios y museos marinos, junto a "arquitecturas de autor". Sin embargo, como explican Porfyriou y Sepe (2017), si bien estos modelos han sido criticados, también han influido en numerosas intervenciones de frentes costeros en distintas regiones del mundo, como, por ejemplo, en el caso analizado de Bilbao. En éste el desarrollo del Museo Guggenheim de Frank Gehry ha sido catalizador de la reconvención ribereña, convirtiendo a la ciudad en un nuevo polo turístico a nivel internacional. En este sentido, si bien las dinámicas del mercado no siempre cambian la imagen de la ciudad, sí incorporan nuevos factores y dinámicas que pueden alejarse en gran medida de la imaginabilidad de los habitantes locales y de su reclamo de cohesión entre el tejido urbano y el río. Es decir, es importante que los bordes, que históricamente por su condición productiva-portuaria constituían "una barrera dominante" (Lynch, 1970, p. 96), no lo continúen siendo en la actualidad por la nueva privatización de espacios o la incorporación de elementos confusos de su imagen total.

Edward Relph (1976, citado por Özgece et al. 2020) sostiene que la imagen de un lugar es su identidad y que comprender algo de la estructura social de sus imágenes es un prerrequisito para poder comprender la identidad. En este sentido, la identidad de cada frente costero está indisociablemente vinculado a la imaginabilidad y la legibilidad del espacio. Es por ello que son tan esenciales 
la visibilidad, la accesibilidad y el uso (Lynch, 1970) de áreas previamente identificadas como barreras para cambiar su imagen. Por lo cual, siguiendo a Özgece et al. (2020), el espacio público resulta clave para incrementar la imagen pública colectiva. Como hemos visto en los distintos casos de estudio presentados, en mayor o menor medida, en todos se incrementó la legibilidad urbana a través de la generación de espacio público junto al agua, posibilitando "muchas conexiones visuales y de circulación con el resto de la estructura urbana" (Lynch, 1970, p. 96).

El caso analizado de la ribera central de Rosario evidencia que su reconversión se inicia de manera continuada e ininterrumpida desde mediados de la década de 1980, pero no es motivada por las transformaciones de waterfronts internacionales previas (como, por ejemplo, Baltimore o Londres), sino que su motor principal radica en responder a los reclamos persistentes de la sociedad desde la década de 1920, que reclaman "dejar de dar la espalda" al Paraná y reconfigurar la relación del río con la ciudad a través de nuevos espacios públicos. También, resulta importante destacar que las intervenciones realizadas en la costa central (especialmente aquellas que se llevan a cabo entre los años 1980-2005), mayormente se centran en la generación de espacio público de acceso pleno y a la refuncionalización de componentes ferro-portuarias en nuevos usos, mayormente culturales, educativos y administrativos públicos.

\section{Conclusiones}

Si bien los casos analizados son diversos, correspondientes a diferentes contextos geográficos, históricos y sociales, presentan puntos en común y su estudio nos arroja luz tanto sobre el rol del diseño urbano como de los efectos e impactos resultantes a su aplicación. Por un lado, es importante destacar que todos se desarrollan a partir de un área productiva/portuaria obsoleta sobre el río, generalmente en conflicto por su yuxtaposición con áreas residenciales, localizada 
en áreas estratégicas y centrales de las ciudades donde se encuentran. A partir de diversas estrategias de diseño, los distintos casos coinciden en la transformación de las características de esos bordes, generando nuevas articulaciones con las sendas perpendiculares que llegan a ellos, como también a generar nuevas sendas en sentido paralelo a los mismos, permitiendo la accesibilidad plena y la continuidad de las personas y fortaleciendo la legibilidad urbana.

En especial en el caso de la reconversión central rosarina se desarrollan nuevos nodos, puntos estratégicos que atraen visitantes, focos de concentración que resultan escenario para las diversas prácticas que realizan los distintos actores de la sociedad. También así, se agregan o se resignifican mojones. Es decir, elementos, componentes clave de la identidad de ese lugar, que permanecen a través de las transformaciones y que consisten en puntos de referencia. Asimismo, estas acciones tienden a tener un rol integrador entre los distintos barrios de la ciudad, ya sea por reposicionar a sectores degradados en nuevas centralidades, como también en articular a distintos barrios entre sí (en toda la extensión del frente fluvial, generando nuevas sendas continuas). En este sentido, la clave justamente es lograr una mayor imaginabilidad urbana a partir de la integración de todos los componentes y elementos. Mediante las distintas estrategias de diseño urbano aplicadas, se parte de la complejidad de la ciudad y se actúa en ellas, como explica Ascher (2007), conservando los valores simbólicos del pasado e integrándolos a las nuevas economías culturales y turísticas.

En la actualidad, frente a las presiones del mercado global y las tendencias homogeneizadoras de paisajes análogos que se replican en distintos rincones del mundo, resulta indispensable mantener la escucha atenta a todas las demandas y voces de los habitantes de la ciudad, con procedimientos propios a debates democráticos y participativos, que promuevan ciudades muy imaginables; es decir, que sean evidentes, legibles y visibles, que articulen sus diversos componentes, sus persistencias y sus flujos, respetando su propia identidad. 


\section{Referencias}

Ascher, F. (2007). Los nuevos principios del urbanismo. Alianza Editorial.

Breen, A. y Rigby, D. (1994). Waterfronts. Cities reclaim their edge. Kim Hupp Lee.

Castrillo, M., Matesanza, A., Sánchez, D. y Sevilla, A. (2014). ¿Regeneración urbana? Deconstrucción y reconstrucción de un concepto incuestionado. Papeles de relaciones ecosociales y cambio global, 126, 129-139.

Clarín. (2015, 9 de febrero). Rosario, de cara al río Paraná. Clarín, Sección viajes.

Cullen, G. (1961). (2012). The concise Townscape. Routledge.

Delgado, M. (2008). La artistización de las políticas urbanas. El lugar de la cultura en las dinámicas de reapropiación capitalista de la ciudad. Scripta Nova, Revista Electrónica de Geografía y Ciencias Sociales, vol. XII, 270(69). http://www.ub.es/geocrit/sn/sn270/sn27069.htm

Della Paolera, C. M., Farengo, A. y Guido, A. (1935). Plan Regulador y de Extensión. Municipalidad de Rosario.

Desfor, G., Laidley, J., Stevens, Q. y Schubert, D. (2011). Transforming Urban Waterfronts. Fixity and Flow. Routledge.

Galimberti, C. (2014). Reflexiones en torno a las transformaciones de waterfronts contemporáneas. Revista Arquitectura y Urbanismo, XXXV(2), 19-35.

Galimberti, C. (2015). La reinvención del río. Procesos de transformación de la ribera de la Región Metropolitana de Rosario. UNR Editora - A\&P Ediciones, Colección Tesis Doctorales.

García-Pérez, S. (2017). Diseño urbano y espacio público en contextos de regeneración urbana integrada: conceptos, marco institucional y experiencias recientes. ZARCH, 8, 214-227. https://doi.org/10.26754/ojs_zarch/zarch.201782157

Harvey, D. (2008). La condición de la posmodernidad: investigación sobre los orígenes del cambio cultural. Amorrortu.

Jacobs, J. (1961). (2011). Muerte y vida de las grandes ciudades. Capitán Swing libros S.L.

La Capital. (1954, 10 de enero). Rosario del futuro. Recuperación del Paraná por el urbanismo. Diario La Capital. 
La Capital. (1992, 7 de junio). Parque España: Un verdadero balcón al río recuperado para todos los rosarinos. Diario La Capital.

La Capital. (2013, 22 de diciembre). García Lorca, crónica de una visita. Diario La Capital.

Laurence, P. (2006). The Death and Life of Urban Design: Jane Jacobs, The Rockefeller Foundation and the New Research in Urbanism, 1955-1965. Journal of Urban Design, 11(2), 145-171.

Lynch, K. (1960). (1970). La imagen de la ciudad. Ediciones Infinito.

Monclús, J. (2016). Urbanismo y regeneración urbana. Siete temas de debate en la cultura urbanística internacional. En J. Monclús Fraga y R. Bambó Naya (Eds.), Regeneración Urbana (III) Propuestas para el barrio Oliver, Zaragoza. Prensas de la Universidad de Zaragoza.

Municipalidad de Rosario. (2011). Plan Urbano Rosario 2007-2017. Secretaría de Planeamiento.

Munizaga, G. (2014). Diseño Urbano. Teoría y Método. Ediciones Universidad Católica de Chile.

Muñoz, F. (2008). Urbanalización. Paisajes comunes, lugares globales. Editorial Gustavo Gili.

Navas, M. G. (2019). La regeneración urbana implementada en Guayaquil y Barcelona. Desvelando la retórica proyectual del espacio público. Bitácora Urbano Territorial, 29(3), 91-100. https://doi.org/10.15446/bitacora.v29n3.70047

Özgece, N., Edgü, E. y Ayiran, N. (2020). Assessing Imageability of Port Cities Through the Visibility of Public Spaces: The Cases of Famagusta and Limassol. Space and Culture, 1-18. DOI: $10.1177 / 1206331220944063$

Parkinson, M. (2014). Regeneración urbana integrada en 2014: nada nuevo bajo el sol y ¿qué pasa con España? Ciudad y territorio: Estudios territoriales, 179, 11-27. https://recyt.fecyt.es/ index.php/CyTET/article/view/76284/46651

Porfyriou, H. y Sepe, M. (2017). Waterfronts Revisited. European ports in a historic and global perspective. Routledge.

Roberts, P. (2000). The Evolution, Definition and Purpose of Urban Regeneration. En P. Roberts y H. Sykes (Eds.), Urban Regeneration. Sage Publications.

Rodríguez, A. (2002). Reinventar la ciudad: Milagros y espejismos de la revitalización urbana en Bilbao. Lan Harremanak, 6, 69-108.

Rowe, C. y Koetter, F. (1998). Ciudad Collage. Gustavo Gili. 
Sautu, R. (2005). Todo es teoría: objetivos y métodos de investigación. Lumiere.

Smith, N. (2006). Gentrification generalized: From local anormaly to urban "regeneration" as global urban strategy. En M. Fisher y G. Downey (Eds.), Frontiers of capital: ethnographic reflections on the new economy (pp. 191-208). Duke University Press.

Cómo citar: Galimberti, C. (2021). El diseño urbano en frentes fluviales como posibilitador de una nueva "imaginabilidad" urbana: caso ribera central de Rosario (Argentina). Revista KEPES, 18(24), 47-78. https://doi.org/10.17151/kepes.2021.18.24.3 